\section{ALCOHOLIC TRANCE IN CRIMINAL} CASES.

Read in the Section of Medical Jurisprudence, at the Fortieth Annual Meeting of the American Medical Association, June, I889.

BY T. D. CROTHERS, M.D., OF HARTFORD, CONN.

SUPERINTENDENT WALNUT LODGE; EDITOR JOURNAL OF INEBRIETY. ETC.

The frequent statement of prisoners in court that they did not remember anything about the crime they are accused of, appears from scientific study to be a psychological fact. How far this is true in all cases has not been determined, but there can be no question that crime is often committed without a conscious knowledge or memory of the act at the time.

It is well known to students of mental science, that in certain unknown brain states memory is palsied, and fails to note the events of life and surroundings. Like the somnambulist, the person may seem to realize his surroundings and be conscious of his acts, and later be unable to recall anything which has happened. These blanks of memory occur in many disordered states of the brain and body, but are usually of such short duration as not to attract attention. Sometimes events that occur in this state may be recalled afterwards, but usually they are total blanks. The most marked blanks of memory have been noted in cases of epilepsy and inebriety. When they occur in the latter they are called alcoholic trances, and are always associated with excessive use of spirits. Such cases are noted in persons who use spirits continuously, and who go about acting and talking sanely, although giving some evidence of brain failure, yet seem to realize their condition and surroundings. Some time after, they wake up and deny all recollection of acts and events for a certain period in the past. This period to them begins at a certain point and ends hours or days after, the interval of which is a total blank, like that of unconscious sleep. Memory and certain brain functions are suspended at this time, while the other brain activities go on as usual. In all probability, the continued paralysis from alcohol not only lowers the nutrition and functional activities of the brain, but produces a local palsy, followed by a temporary failure of consciousness and memory, which after a time passes away.

When a criminal claims to have had no memory or recollection of the crime of which he is accused, if his statement is true, one of two conditions is probably present, either epilepsy or alcoholism. Such a trance state might exist and the person be free from epilepsy and alcoholism, but from our present knowledge of this condition it would be difficult to determine this fact. If epilepsy can be traced in the history of the case, the trance state has a pathological basis for its presence. If the prisoner is an inebriate, the same favoring conditions are present. If the prisoner has been insane, and suffered from sun or heat stroke, and the use of spirits are the symptoms of brain degeneration, the trance state may occur any time. The fact of the actual existence of the trance state is a matter for study, to be determined from the history of the person and his conduct; a grouping of evidence that the person cannot simulate or falsify, evidence that turns not on any one fact, but on an assemblage of facts that point to the same conclusion.

The following cases are given to illustrate some of these facts, which support the assertion of no memory of the act by the prisoner in court:

The first case is that of A., who was repeatedly arrested for horse stealing, and always claimed to be unconscious of the act. This defense was regarded with ridicule by the court and jury, and more severe sentences were imposed, until finally he died in prison. The evidence offered in different trials in defense was, that his father was weakminded and died of consumption, and his mother was insane for many years, and died in an asylum. His early life was one of hardship, irregular living, and no training. At 16 he entered the army, and suffered from exposure, disease and sunstroke, and began to drink spirits to excess at this time. At 20 he was employed as a hack driver, and ten years later became owner of a livery stable. $\mathrm{He}$ drank to excess at intervals, yet during this time attended to business, acting sanely, and apparently conscious of all his acts, but often complained he could not recollect what he had done while drinking. When about 34 years of age he would, while drinking, drive strange horses to his stable, and claim that he had bought them. The next day he had no recollection of these events, and made efforts to find the owners of these horses and return them. It appeared that while under the influence of spirits the sight of a good horse hitched up by the roadside alone, created an intense desire to possess and drive it. If driving his own horse, he would stop and place it in a stable, then go and take the new horse, and after a short drive put it up in his own stable, then go and get his own horse. The next day all this would be a blank, which he could never recall. On several occasions he displayed reasoning cunning, in not taking a horse when the owners or drivers were in sight. This desire to possess the horse seemed under control, but when no one was in sight all caution left him, and he displayed great boldness in driving about in the most public way. If the owner should appear and demand his property he would give it up in a confused, abstract way. No scolding or severe language made any impression on him. Often if the horse seemed weary he would place it in the nearest stable, with strict orders to give it special care. On one occasion he joined in a search for a stolen horse, and found it in a stable 
where he had placed it many days before. O this he had no recollection. In another instance he sold a horse which he had taken, but did not take any money, making a condition that the buyer should return the horse if he did not like it. His horse stealing was all of this general character. No motive was apparent, or effort at concealment, and on recovering from his alcoholic excess, he made every effort to restore the property, expressing great regrets, and paying freely for all losses. The facts of these events fully sustained his assertion of unconsciousness, yet his apparent sanity was made the standard of his mental condition. The facts of his heredity, drinking, crime and conduct, all sustained his assertion of unconsciousness of these events. This was an alcoholic trance state, with kleptomaniac impulses.

The next case, that of B., was executed for the murder of his wife. He asserted positively that he had no memory or consciousness of the act, or any event before or after. The evidence indicated that he was an inebriate of ten years' duration, dating from a sunstroke. He drank periodically, for a week or ten days at a time, and during this period was intensely excitable and active. He seemed always sane and conscious of his acts and surroundings, although intensely suspicious, exacting, and very irritable to all his associates. When sober he was kind, generous and confiding, and never angry or irritable. He denied all memory of his acts during this period. While his temper, emotions, and conduct were greatly changed during this time, his intellect seemed more acute and sensitive to all his acts and surroundings. His business was conducted with usual skill, but he seemed unable to carry out any ora! promises, claiming he could not recollect them. His business associates always put all bargains and agreements in writing when he was drinking, for the reason he denied them when sober. But when not drinking his word and promise was always literally carried out. $\mathrm{He}$ broke up the furniture of his parlor when in this state, and injured a trusted friend, and in many ways showed violence from no cause or reason, and afterwards claimed no memory of it. After these attacks were over, he expressed great alarm and sought in every way to repair the injury. Finally he struck his wife with a chair and killed her, and awoke the next day in jail, and manifested the most profound sorrow. While he disclaimed all knowledge of the crime, he was anxious to die and welcomed his execution. This case was a periodical inebriate with maniacal and homicidal tendencies. His changed conduct, and unreasoning, motiveless acts, pointed to a condition of trance. His assertion of no memory was sustained by his conduct after, and efforts to find out what he had done and repair the injury. The third case, that of $\mathrm{C}$., was a man of wealth by the facts. and character who forged a large note, drew the money and went to a distant city on a visit. He was tried and sentenced to State prison. The defense was no memory or consciousness of the act by reason of excessive use of alcohol. This was treated with ridicule. Although he had drank to excess at the time of and before the crime, he seemed rational and acted in no way as if he did not understand what he was doing. Both his parents were neurotics, and he began to drink in early life, and for years was a moderate drinker. He was a successful manufacturer, and only drank to excess at times for the past five years. He complained of no memory during these drink paroxysms, and questioned business transactions and bargains he made at this time. On one occasion he went to New York and made foolish purchases which he could not recall. On several occasions he discharged valuable workmen, and when he became sober took them back, unable to account for such acts. These and other very strange acts continued to increase with every drink excess. At such times he was reticent and seemed to be sensible and conscious, and did these strange acts in a sudden, impulsive way. The forged note was offered boldly, and no effort was made to conceal his presence or destination. When arrested he was alarmed and could not believe that he had done so foolish an act. This was a clear case of alcoholic trance, in which all the facts sustained his assertion of no conscious memory of the crime. In these three cases the correctness of the prisoners' assertions of no memory was verified by all the facts and circumstances of the crime. The mere statement of a person accused of crime, that he had no memory of the act, should lead to a careful examination and be only accepted as a fact when it is supported by other evidence.

The following case illustrates the difficulty of supporting a prisoner's statement of no memory when it is used for purposes of deception:

Case E.-An inebriate killed a man in a fight, and was sentenced to prison for life. He claimed no memory or recollection of the act. I found that when drinking he seemed conscious of all his surroundings, and was always anxious to conceal his real condition, and if anything had happened while in this state he was very active to repair and hush it up. He was at times quite delirious when under the influence of spirits, but would stop at once if any one came along that he respected. He would, after acting wildly, seem to grow sober at once, and do everything to restore the disorder he had created. The crime was an accident, and at once he attempted concealment-ran away, changed his clothing, and tried to disguise his identity; when arrested, claimed no memory or consciousness of the act. This claim was clearly not true, and contradicted 
In a recent case $\mathrm{F}$. shot his partner in business while both were intoxicated, and displayed great cunning to conceal the crime and person; then, after elaborate preparations, went away. $\mathrm{He}$ made the same claim of defense, which was unsupported by any other evidence or facts in his previous life. He was executed. Of course it is possible for the trance state to come on suddenly, and crime be committed at this time; still, so far, all the cases studied show that this condition existed before, and was the product of a growth beginning in brief blanks of a few moments and extending to hours' and days' duration. Unless the facts indicated the trance state before the crime was committed, it would be difficult to establish this condition for the first time, followed and associated with the crime.

I think in most of these cases, where this defense is set up, there will be found certain groups of cases that have common physical conditions of degeneration. These groups of cases I have divided from a clinical standpoint, the value of which will be more as an outline for future studies.

Probably the largest number of criminal inebriates who claim loss of memory as a defense for their acts are the alcoholic dements. This class are the chronic inebriates of long duration : persons who have naturally physical and mental defects, and who have used spirits to excess for years. This, with bad training in early life, bad surroundings, and bad nutrition, have made them of necessity unsound, and liable to have many and complex brain defects. Such persons are always more or less without consciousness or realization of their acts. They act automatically only, governed by the lowest and most transient impulses. Crimes of all kinds are generally accidents growing out of the surroundings, without premeditation or plan. They are incapable of sane reasoning or appreciation of the results of their conduct. The crime is unreasoning, and general indifference marks all their acts afterwards. The crime is always along lines of previous conduct, and never strange or unusual. The claim of no memory in such cases has always a reasonable basis of truth in the physical conditions of the person. Mania is very rarely present, but delusions and morbid impulses of a melancholic type always exist. The mind, like the body, is exhausted, depressed, and acts along lines of least resistance.

The second group of criminals who claim no memory are those where the crime is unusual, extraordinary, and unforeseen. Persons who are inebriates suddenly commit murder, steal, or do some criminal act that is foreign to all previous conduct. In such cases the trance condition may have been present for some time before and escaped any special notice, except the mere statement of the person that he could not recollect his acts. The unusual nature of the crime, committed by persons who never before by act or thought gave any indication of it, is always a factor sustaining the claim of no memory. The explosive, unreasoning character of crime always points to mental unsoundness and incapacity of control.

A third group of criminals urge this statement of no memory, who, unlike the first group, are not imbeciles generally. They are positive inebriates, drinking to excess, but not to stupor, who suddenly commit crime with the most idiotic coolness and indifference, never manifesting the slightest appreciation of the act as wrong, or likely to be followed by punishment. Crime committed by this class is never concealed, and the criminal's after conduct and appearance gives no intimation that he is aware of what he has done. These cases have been termed moral paralytics, and the claim of the trance state may be very likely true.

A fourth group of cases where memory is claimed to be absent occurs in dipsomaniacs and periodical inebriates, who have distinct free intervals of sobriety. This class begin to drink to great excess at once, then drink less for a day or more, and begin as violently as ever again. In this short interval of moderate drinking some crime is committed of which they claim not to have any recollection.

Other cases have been noted where a condition of mental irritation or depression preceded the drink explosion, and the crime was committed during this premonitory period, and before they drank to excess. The strong probability of trance at this period is sustained by the epileptic character of such conduct afterwards. The trance state may justly be termed a species of aura, or brain paralysis, which precedes the explosion.

In some instances, before the drink storm comes on, the person's mind would be filled with the most intense suspicions, fears, delusions, and exhibit a degree or irritation and perturba. tion unusual and unaccountable. Intense excitement or depression, from no apparent cause, prevails, and during this period some crime may be committed; then comes the drink paroxysm, and later all the past is a blank. Trance is very likely to be present at this time.

In these groups the crime is generally automatic, or committed in a manner different from other similar crimes. Some governing center has suspended, and all sorts of impulses may merge into acts at any moment. The consciousness of acts and their consequences are broken up. The strong probability is that these trance blanks begin in short periods of unconsciousness, which lengthen with the degeneration and mental feebleness of the person. The obscurity of these conditions, and the incapacity of the victims to realize their import, also the absence of any special study, greatly increases the difficulty. It will be evident from inquiry that trance states 
among inebriates are quite common, but seldom listic or bypnotic state. The duration of this attract attention unless they come into legal state may be from a few moments to several days, notice. The practical question to be determined and the person at this time may appear conscious in a given case in court is the actual mental condition of the prisoner, who claims to have no recollection of the crime. This a class of evidence that must be determined by circumstantial and collateral facts, which require scientific expertness to gather and group. The court can decide from the general facts of the crime and the prisoner whether his claim of no memory may possibly be true, and order an expert examinaation to ascertain the facts. This should be done in all cases where the prisoner is without means, in the same way that a lunacy commission is appointed to decide upon the insanity. The result of this expert study may show a large preponderance of evidence sustaining the claim of no memory, or the opposite. If the former, the meastire of the responsibility must be modified, and the degree of punishment changed. While such cases are practically insane at the time, and incapable of realizing or controlling their acts, they should be kept under legal and medical surveillance for a lifetime, if necessary. Such men are dangerous, and should be carefully watched and deprived of their liberty for a length of time depending on recovery and capacity to act rationally and normally. They are dangerous diseased men, and, like victims of contagious disease, must be housed and treated.

The future of such cases depends on the removal of the causes which made them what they are. The possibility of permanent restoration is very promising in most cases. How far alcoholic trance exists in criminal cases is unknown, but the time has come when such a claim by criminals cannot be ignored, and must be the subject of serious inquiry. Such a claim cannot be treated as a mere subterfuge to avoid punisinment, but should receive the same attention that a claim of insanity or self-defense would. This is only an outline view of a very wide and most practical field of medico-legal research, largely unknown, which can be seen in every court room of the land. These cases appeal to us for help and recognition, and the highest dictates of humanity and justice demand of us an accurate study and comprehension of their nature and character.

The following summary of the leading facts in this trance condition will be a standpoint for other and more minute investigations :

Ist. The trance state in inebriety is a distinct brain condition, that exists beyond all question or doubt.

2d. This brain state is one in which all memory and consciousness of acts or words are suspended, the person going about automatically, giving littie or no evidence of his real condition.

${ }_{j} \mathrm{~d}$. The higher brain centers controlling consciousness are suspended, as in the somnambuand act naturally, and along the line of his ordinary life.

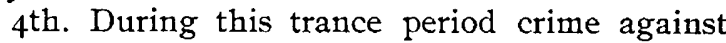
person or property may be committed without any motive or apparent plan, usually unforeseen and unexpected. When accurately studied such a crime will lack in the details and methods of execution, and also show want of consciousness of the nature and results of such acts.

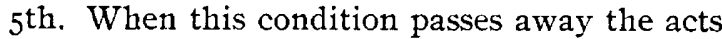
and conduct of the person show that he did not remember what he had done before. Hence his denial of all recollection of past events, and his changed manner confirm or deny his statements.

6 th. When such cases come under judicial inquiry the statement of the prisoner requires a scientific study before it can be accepted as a probable fact. It cannot be simulated, but is susceptible of proof beyond the comprehension of the prisoner.

7 th. In such a state crime and criminal impulses are the result of unknown and unforeseen influences, and the person in this condition is dangerous and an irresponsible madman.

$8 \mathrm{th}$. This condition should be fully recognized by court and jury, and the measure of responsibility and punishment suited to each case. They should not be punished as criminals, nor should they be liberated as sane men. They should be housed and confined in hospitals.

\section{ON THE ORGANIZATION AND ABSORP- TION OF STERILIZED DEAD BONE DOWELS.}

Read in the Section of Surgery and Anatomy, at the Fortieth Annual Meeting of the American Medical Association, June, 1889 .

BY WILIIAM BARTON HOPKINS, M.D., SURGEON TO THE EPISCOPAL HOSPITAL, AND SURGEON TO OUTDEPARTMENT OF PENNSYLVANIA HOSPITAL AND B

CHARLES B. PENROSE, M.D., Ph.D.,

ASSISTANT SURGEON TO THE HOSPITAL OF THE LNIVERSITY OF PENNSYIVANIA; SURGEON TO OUT-DEPARTMENT OF PENNSYLVANIA HOSPITAI.

Mr. Wm. Scovell Savory, in I 864, demonstrated, by a series of experiments performed upon various animals, principally the rabbit, that ivory pegs driven into healthy living bone would, after a time, undergo greater or less absorption. $\mathrm{He}$ found, however, that in order to obtain this result, it was necessary that the peg be driven tightly into a hole which was a trifle too small for it. Upon this observation, he concluded that firm pressure upon the surface of dead bone against the living was the essential factor in cansing the absorption. His experiments were, of course, done long before the antiseptic era, and we may 